\title{
Antibacterial Properties of Honey from Different Algerian Regions against Staphylococcus aureus Strains from Wounds
}

\author{
M. Bouacha ${ }^{1}\left(\mathbb{D}\right.$ and H. Benbouzid ${ }^{2 *}$ (I) \\ ${ }^{1}$ Laboratory of Biochemistry and Applied Microbiology, Department of Biochemistry, Faculty of Sciences, Badji \\ Mokhtar - Annaba University, Algeria. ${ }^{2}$ Laboratory of Cell Toxicology, Department of Biology, Faculty of Sciences, \\ Badji Mokhtar - Annaba University, Algeria.
}

\begin{abstract}
Human beings have used honey for the treatment of several bacterial infections, particularly, in wound infections. The objective of this study is to evaluate the effectiveness of Algerian honey to eradicate Staphylococcus aureus. The antibacterial effect of honey samples was carried out on four strains of $S$. aureus (two are methicillin-resistant and two are methicillin-sensitive) by using well diffusion assay, dilution assay, and a time-kill curve assay. The results revealed that Algerian honey has measurable antibacterial activity on both resistant and methicillin-sensitive strains. The inhibitory diameters ranged from 34.33 to $52 \mathrm{~mm}$, the MIC values range from 2.5 to $5 \%(\mathrm{w} / \mathrm{v})$ and the $\mathrm{MBC}$ values range from 2.5 to $10 \%(w / v)$. Algerian honey has enormous potential as a useful source against $S$. aureus strains, including MRSA strains. Therefore, it is necessary to characterize the active components of tested honey to investigate the possible use of honey in the treatment of infections caused by MRSA strains.
\end{abstract}

Keywords: MIC, MBC, time-kill assay, S. aureus, infection diseases, Algerian honey

*Correspondence: houneida.benbouzid@gmail.com

(Received: September 08, 2019; accepted: January 27, 2020)

Citation: M.Bouacha and H. Benbouzid, Antibacterial Properties of Honey from Different Algerian Regions against Staphylococcus aureus Strains from Wounds, J. Pure Appl. Microbiol., 2020; 14(1):447-453. https://doi.org/10.22207/JPAM.14.1.46

(C) The Author(s) 2020. Open Access. This article is distributed under the terms of the Creative Commons Attribution 4.0 International License which permits unrestricted use, sharing, distribution, and reproduction in any medium, provided you give appropriate credit to the original author(s) and the source, provide a link to the Creative Commons license, and indicate if changes were made. 


\section{INTRODUCTION}

Staphylococcus aureus is a very important bacterial species in nosocomial and community infections, it is responsible for increased morbidity and mortality in hospitals worldwide ${ }^{1}$.

Currently, this bacterium is resistant to many initially active antibiotics and strains isolated from nosocomial infections can resist not only to penicillin $G$ but also to penicillin $M$ (methicillin, oxacillin $)^{1,2}$. The only treatment against methicillinresistant $S$. aureus (MRSA) is based on the use of glycopeptides ${ }^{2,3}$. However, since the first vancomycin-resistant strain appeared in Japan in $1997^{4}$, therapeutic failures related to the frequent use of vancomycin have been reported ${ }^{5}$; to overcome this problem of multiresistance of S. aureus strains, a research for new powerful antimicrobial agents must be established.

The use of traditional medicine to treat infection has been practiced since the origin of mankind, and honey produced by Apis mellifera is one of the oldest traditional medicines considered to be as a traditional remedy for microbial infections ${ }^{6}$. Honey has inhibitory effects against approximately 60 bacterial species; including aerobes and anaerobes, Gram-positive and Gramnegative bacteria ${ }^{7}$. Honey has a complex chemistry, and its broad-spectrum antimicrobial activity varies with floral source, climate and harvesting conditions ${ }^{8}$. The precise mode of action of honey is unknown. However, there are several factors responsible for its antimicrobial activity include high osmolarity, low $\mathrm{pH}$, hydrogen peroxide, and non-peroxide factors include lysozyme, phenolic acids and flavonoids ${ }^{9}$. Nonetheless, honey sample from different floral sources showed various levels of antimicrobial activity ${ }^{7,10}$. However, variation in this activity among honey types from within the same floral species has also been observed ${ }^{7,11,12}$.
This may be due to the geographical location of the floral source and the prevailing environmental conditions, which affect the physiology of the floral species ${ }^{11,13}$. So, the quality of honey varied based on the geographical floral origin, season, environmental factors, and storage conditions ${ }^{11,14}$.

Algeria has a great floral diversity, there are about 3000 plant species of which $15 \%$ are endemic. This potential for medicinal plants includes thousands of species of diverse interest and it is a focus of scientific research, particularly in the field of natural substances. However, to the best of our knowledge, very few studies have been carried out on Algerian natural products, and no published data exist on the antimicrobial activity of most of Algerian honey types ${ }^{14}$. Therefore, the objective of this study is to investigate the antibacterial activity of three Algerian honey samples on the growth and viability of S.aureus strains including methicillin-susceptible S.aureus (MSSA) and methicillin-resistant S.aureus (MRSA), with taking into account the floral and the geographical origin differences.

\section{MATERIALS AND METHODS Honey samples}

The sampling honeys used in this study were collected from three different Algerians sites with different climatic level and a rich floral diversity (Table 1). All the samples were collected in September 2018 and stored in dark glass bottles at $4^{\circ} \mathrm{C}$. Different concentrations of honey samples were prepared in saline sterile solution: $2.5 \%, 5 \%$, $10 \%, 20 \%, 40 \%, 80 \%(\mathrm{w} / \mathrm{v})$, and undiluted honey. All honey samples were filtered through a $0.22 \mu \mathrm{m}$ filter (Nunc, USA).

\section{Tested strains}

The antibacterial activity of honey samples was screened against bacterial strains of $S$. aureus;

Table 1. Botanical and geographical origins of honey samples

\begin{tabular}{|c|c|c|c|}
\hline & Geographical origin & Climate & Floral origin \\
\hline Sample 1 & $\begin{array}{l}\text { El Taref: located in extreme } \\
\text { north-eastern Algeria }\end{array}$ & Mediterranean climate & Citrus: Orange, Lemon \\
\hline Sample 2 & $\begin{array}{l}\text { Djelfa: located in the } \\
\text { central part of north Algeria } \\
\text { beyond the foothills }\end{array}$ & $\begin{array}{l}\text { A semi-arid to an arid } \\
\text { climate }\end{array}$ & $\begin{array}{l}\text { Ruta, Ziziphus, Artemisia, } \\
\text { Marrubium }\end{array}$ \\
\hline Sample 3 & $\begin{array}{l}\text { Skikda: located in north- } \\
\text { eastern Algeria }\end{array}$ & Mediterranean climate & Quercus, Chestnut \\
\hline
\end{tabular}


two are susceptible to methicillin (MSSA): S. aureus ATCC 25923 and a clinical strain, two others are resistant to methicillin (MRSA): S. aureus ATCC 43300 and a clinical strain. An inoculum of each strain of approximately $10^{6} \mathrm{CFU} / \mathrm{ml}$ was prepared in nutrient broth. The standard strains were provided by the bacteriology laboratory (Pasteur's Institute of Algiers, Algeria). The pathogenic strains have been isolated from wounds and identified using the Gram staining, oxidase and catalase tests, and API STAPH (Biomerieux, France). These strains were subjected to methicillin susceptibility tests using cefoxitin disk test, and the screening test in Mueller-Hinton agar supplemented with $4 \% \mathrm{NaCl}$ and containing $6 \mu \mathrm{g} / \mathrm{ml}$ of oxacillin. The tested strains were selected for comparison the susceptibility difference between MRSA and MSSA strains to honey samples.

\section{Analysis of honey samples \\ Sensory analysis}

The sensory analysis consists to evaluate the properties of honey by a color and flavors examination to understand their relationship on antibacterial activity.

\section{pH measurement}

The $\mathrm{pH}$ of each honey sample diluted to $50 \%(\mathrm{w} / \mathrm{v})$ was measured using a $\mathrm{pH}$ meter $(\mathrm{HI}$ 98127, Hanna instruments, Mauritius).

\section{Color intensity}

The mean absorbance expressed as $\mathrm{mAU}$ was measured at 450 and $720 \mathrm{~nm}$ according to the method of Beretta et al. (2005) of the diluted honey samples to $50 \%(\mathrm{w} / \mathrm{v})$ in warm water $(45$ $50^{\circ} \mathrm{C}$ ), and filtered to eliminate large particles using a $0.45 \mu \mathrm{m}$ filter. The equipment used to measure the absorbance was a spectrophotometer (T80 UV/VIS England).

\section{Antibacterial activity \\ Wells assay}

The wells of $6 \mathrm{~mm}$ of diameter were prepared in Petri dishes containing Mueller Hinton agar and inoculated by the bacterial suspension. Honey samples $(150 \mu l)$ were added in each well and a well containing distilled water was used as a control. After $24 \mathrm{~h}$ at $37^{\circ} \mathrm{C}$, the antibacterial activity of the samples was determined by measuring the clear inhibition zone around the wells.

\section{MIC determination}

Minimum inhibitory concentrations (MICs) were determined using tubes containing
$0.5 \mathrm{~mL}$ of inoculum prepared in sterile nutrient broth corresponding to 0.5 Mac-Farland added to $4.5 \mathrm{~mL}$ of each concentration of honey tested. The negative control contained bacterial inoculum and positive control contained just broth. All tubes were incubated at $37^{\circ} \mathrm{C}$ for $24 \mathrm{~h}$ in the dark with shaking at $150 \mathrm{rpm}$. The optical density was measured at T0 and again after $24 \mathrm{~h}$ (T24) at $620 \mathrm{~nm}$. The percent inhibition of growth was calculated by the following formula:

$$
\text { Percent of inhibition(\%) }=1-\frac{\text { ODtest }}{\text { ODcontrol }} \times 100
$$

The MIC is the concentration of honey dilution totally inhibiting bacterial growth visible after $24 \mathrm{~h}$ of incubation at $37^{\circ} \mathrm{C}$ (Park et al., 2017).

\section{Determination of MBC}

The $M B C$ value corresponds to the lowest concentration of honey allowing reduction of $99.9 \%$ in the viable strains. $0.1 \mathrm{~mL}$ of the MIC mixtures tube that showed no growth was inoculated on the Mueller Hinton plates and incubated during $24 \mathrm{~h}$ at $37^{\circ} \mathrm{C}$.

\section{Time-kill assay}

Time-Kill assay is made to evaluate the effect of honey samples on bacterial growth. In a first step, each strain was inoculated in Mueller Hinton broth by a single colony-forming unit (CFU) and grown for $18 \mathrm{~h}$ at $37^{\circ} \mathrm{C}$ with constant stirring at $150 \mathrm{rpm}$. In the second step, each culture was adjusted to 0.5 on the McFarland scale and inoculated at a cell density of $10^{6} \mathrm{CFU} /$ $\mathrm{ml}$ in two tubes, each containing $1 \mathrm{ml}$ of Mueller Hinton broth. One culture received honey at concentration of $20 \% \mathrm{w} / \mathrm{v}$ and the control culture did not receive honey. During the incubation at $37^{\circ} \mathrm{C}$ with constant stirring $150 \mathrm{rpm}$, broth aliquots were collected at different time points, diluted in series in saline solution, plated on Mueller Hinton agar media and incubated for $18 \mathrm{~h}$ at $37^{\circ} \mathrm{C}$ to determine the total CFUs in each culture.

Table 2. Characterization of honey samples

\begin{tabular}{|c|c|c|c|c|}
\hline $\begin{array}{l}\text { Honey } \\
\text { sample }\end{array}$ & Taste & $\mathrm{pH}$ & Color & $\begin{array}{l}\text { Color intensity } \\
\qquad(\mathrm{mAU})\end{array}$ \\
\hline Sample 1 & Sweet & 3.86 & Light brown & 89 \\
\hline Sample 2 & Bitter & 4.27 & Dark brown & 2197 \\
\hline Sample 3 & Bitter & 3.71 & Light brown & 346 \\
\hline
\end{tabular}




\section{Statistical analysis}

The results were expressed as mean \pm standard deviation $(\mathrm{m} \pm \mathrm{SD})$. The data were analyzed by using the software GraphPad Prism 5. Statistical analysis was performed using a one way ANOVA (analysis of variance) followed by a post hoc Tukey's test to evaluate the differences in the zone of inhibition between the honey samples and strains.

\section{RESULTS}

\section{Honey analysis}

The taste, $\mathrm{pH}$ values, and color intensity of honey samples were reported in Table 2 . Sample 1 has a sweet taste, whereas samples 2 and 3 have a bitter taste. As shown, all honey samples were acidic within the standard limit (pH $3.40-6.10)$ that ensures honey samples' freshness. The color intensity of honey sample varied from 89 for the light honey to 2197 mAU for the dark honey.

\section{Antibacterial activity Well diffusion assay}

The results of assessments of honey antibacterial activity against the standard and the clinical strains of $S$. aureus are reported in Tble 3. The Algerian honey has shown good antibacterial activity against all tested strains of $S$. aureus, with diameters of inhibition ranged from 34.33 to 52 $\mathrm{mm}$ for both MRSA and MSSA strains. There are no significant differences between susceptibility of different strain $(p=0.9898)$. However, there are highly significant differences between antibacterial activities of honey samples ( $p<0.001)$. The Djelfa's honey showed strong antibacterial activity, followed by El Taref's honey and that of Skikda.

\section{Dilution assay}

The results of the MICs determination of honey samples are reported in Table 4. All honey samples have shown highly potent activity against all strains of $S$. aureus, the MICs values are ranging

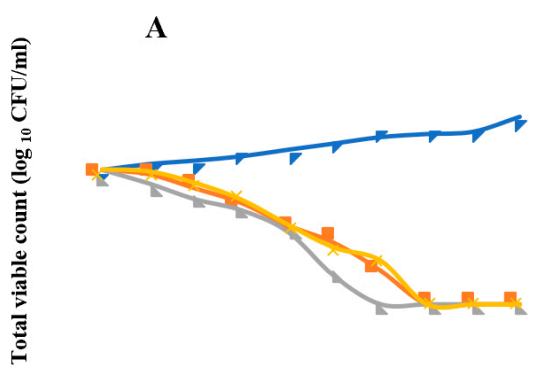

Time (h)

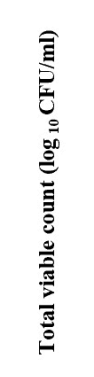

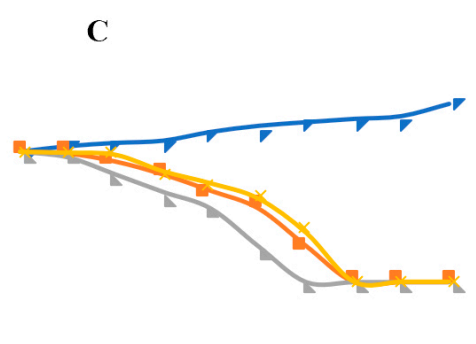

Time (h)

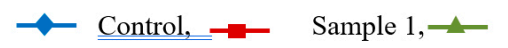

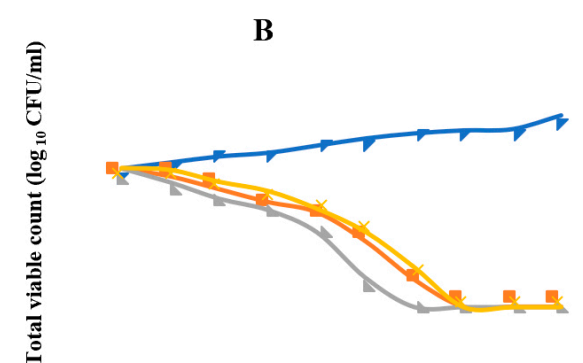

Time (h)

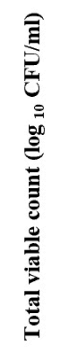

D

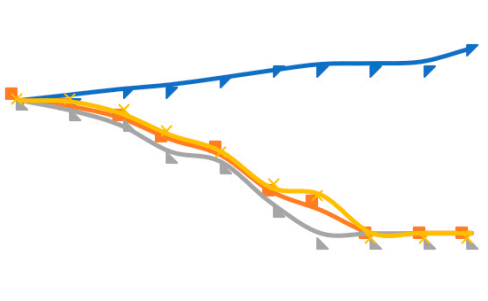

Time (h)

Sample 2, $\longleftarrow \quad$ Sample 3 .

Fig. 1. Effect of honey samples on the growth of $S$. aureus strains.

A: S. aureus ATCC 25923, B : methicillin susceptible S.aureus, C : S. aureus ATCC 43300, D :methicillin susceptible S.aureus. 
Table 3. Diameters of inhibition of honey samples against S.aureus strains ( $\mathrm{mm} \pm \mathrm{SD}$ )

\begin{tabular}{lcccc}
\hline \multirow{2}{*}{ Strains } & & \multicolumn{3}{c}{ Inhibitory diameters $(\mathrm{mm} \pm \mathrm{SD})$} \\
\cline { 3 - 5 } & & Sample 1 & Sample 2 & Sample 3 \\
\hline \multirow{2}{*}{ MSSA } & S. aureus ATCC 25923 & $40.3 \pm 0.8$ & $51.3 \pm 0.4$ & $35 \pm 0.6$ \\
\multirow{2}{*}{ MRSA } & S. aureus (MSSA) & $39.7 \pm 1.1$ & $52 \pm 0.6$ & $34.7 \pm 0.4$ \\
& S. aureus ATCC 43300 & $39 \pm 0.6$ & $48 \pm 1.3$ & $34.3 \pm 0.4$ \\
& S. aureus (MRSA) & $38.7 \pm 0.4$ & $49.3 \pm 0.4$ & $34.7 \pm 1.1$ \\
\hline
\end{tabular}

MSSA: Methicillin-Susceptible S.aureus; MRSA: Methicillin-resistant S.aureus

from 2.5 to $5 \%(\mathrm{w} / \mathrm{v})$, while the MBCs values are ranging from 2.5 to $10 \%(\mathrm{w} / \mathrm{v})$. Honey from Djelfa showed the lowest MICs and MBCs values (2.5\%) compared to other tested honeys.

\section{Time-kill assay}

An evaluation of the kinetics of antibacterial effect of honey samples against MRSA and MSSA strains was performed by constructing a time-kill curve (Fig. 1). We observed a decrease of bacterial growth after the first hour of incubation. After six hours, honey from Djelfa has completely inhibited the growth of all tested strains; the other honey samples have inhibited growth after seven hours of incubation.

\section{DISCUSSION}

In recent years, MRSA has become resistant to several other antibiotics often used in the treatment of MRSA infections, in particular, quinolone, macrolide, aminoglycosides, tetracycline, sulfamethoxazole-trimethoprim, clindamycin and chloramphenicol ${ }^{1,15}$. Therefore, there is an important need to develop more effective antibacterial agents to treat infections caused by S.aureus strains including MRSA strains. Therefore, there is an important need to develop more effective antibacterial agents to treat infections caused by S.aureus strains including MRSA strains. In this study, the antibacterial activity of three Algerian honey samples was investigated against $S$. aureus strains.

As shown in Table 2, the $\mathrm{pH}$ values of honey samples showed that all honey samples were acidic and the $\mathrm{pH}$ values ranged from 3.86 to 4.27 . The $\mathrm{pH}$ values of Algerian honey samples have been previously reported to be between 3.70 and $4.34^{16}$. The acidity of any honey types is directly related to floral sources and to the composition of the honey. Honey contains several different acids, including about 18 amino acids, many different organic acids, as well as aliphatic and aromatic acids that contribute greatly to the flavor of honey ${ }^{16,17}$.

The absorbance of a $50 \%(\mathrm{w} / \mathrm{v})$ honey solution varied from $98 \mathrm{mAU}$ for the light honey to $2197 \mathrm{mAU}$ for the dark brown honey. When compared with the honey samples from other countries, the color intensity values were reported to be between 25 and 3413 mAU in Italian honey ${ }^{18}$, between 724 and $1188 \mathrm{mAU}$ in Algerian honey ${ }^{16}$, and between 254 and 2034 mAU in Bangladeshi honey ${ }^{17}$. This marked difference of color intensity

Table 4. MICs and MBCs values of tested honeys against S. aureus strains (\% w/v)

\begin{tabular}{|c|c|c|c|c|c|c|c|}
\hline & \multirow[t]{2}{*}{ Strain } & \multicolumn{2}{|c|}{ Sample 1} & \multicolumn{2}{|c|}{ Sample 2} & \multicolumn{2}{|c|}{ Sample 3} \\
\hline & & MIC & $\mathrm{MBC}$ & $\mathrm{MIC}$ & $\mathrm{MBC}$ & $\mathrm{MIC}$ & $\mathrm{MBC}$ \\
\hline \multirow[t]{2}{*}{ MSSA } & S. aureus ATCC 25923 & 5 & 5 & 2.5 & 2.5 & 5 & 10 \\
\hline & S. aureus (MSSA) & 5 & 5 & 2.5 & 2.5 & 5 & 10 \\
\hline \multirow[t]{2}{*}{ MRSA } & S. aureus ATCC43300 & 5 & 5 & 2.5 & 2.5 & 5 & 10 \\
\hline & S. aureus (MRSA) & 5 & 10 & 2.5 & 2.5 & 5 & 10 \\
\hline
\end{tabular}

MSSA: Methicillin Susceptible S.aureus, MRSA: Methicillin resistant S.aureus 
might be a reliable index of the presence of pigments with antioxidant activities, such as carotenoids and some flavonoids, which are known to have antioxidant properties ${ }^{8}$. This result confirms the finding of Khalil et al., 2012 which has reported previously that Algerian honey possesses very potent antioxidant activities.

In comparing the effect of honey against MRSA strains and MSSA strains, there is no difference between the susceptibility of MRSA and MSSA strains $(P>0.05)$. Similar findings are reported previously by other authors ${ }^{10,19}$. However, there are highly significant differences between the antibacterial activities of honey samples $(P<0.001)$. These results proved that Honey's antibacterial activity is associated with the floral source. These findings are reported previously by other authors ${ }^{9,20,21}$. The honey sample from Djelfa has a great antimicrobial activity as compared to those from El-Taref and Skikda from the same climate and different floral sources. The rich floral diversity of these regions seems to play an important role in influencing honey's antimicrobial activity. Indeed, in this study we reported that the antibacterial activity of Djelfa's honey may be related to the color of honey which has a dark color compared to other samples which have a light color. This finding agrees with those reported by several studies in which dark honey from the conifer forests of the mountainous regions of central Europe have been found to have particularly high activity ${ }^{10,22}$. It partly derived from honeydew.

Moreover, in order to evaluate the effect of honey samples on bacterial cell viability, the time-kill curves for MRSA and MSSA strains were performed. It showed that the treatment of S.aureus strains with Djelfa's honey was successful in killing within six hours, while the treatment of the same strains with the samples of El-Taref and Skikda was in killing within seven hours. Similar study by Jantakee and Tragoolpua, (2015) has shown that honey destroys S. aureus strains in eight hours with a concentration of $50 \%$. Furthermore, the study of time-kill curve indicated a bactericidal rather than bacteriostatic effect of tested honey samples on $S$. aureus strains. The bactericidal action of honey seems to be dependent on the time of honey action and the bacterial species ${ }^{23}$.
It varies from several to 40 hours (Molan 1992). The concentration of honey also plays an important role. We have tested the concentration of $20 \%(\mathrm{w} / \mathrm{v})$. Jantakee and Tragoolpua, (2015) have reported that honey concentrations from 5 to $50 \%$ have been found to be bactericidal. Generally, the higher the concentration, the faster the bactericidal action can take place.

\section{CONCLUSION}

Algerian honey samples tested in this study have potent antimicrobial activity against S. aureus strains including MSSA and MRSA strains. It appeared to deserve further investigation into its effect on cellular and molecular targets. It may prove to be valuable therapeutic honey which will be used particularly in the treatment of infections with MRSA strains.

\section{ACKNOWLEDGMENTS}

None.

\section{CONFLICT OF INTEREST}

The authors declare that there is no conflict of interest.

\section{FUNDING}

None.

\section{AUTHORS' CONTRIBUTION}

BM carried out the experimental part and wrote the manuscript and $\mathrm{BH}$ developed the theory and performed the computation. The two authors discussed the results and contributed to the final manuscript.

\section{DATA AVAILABILITY}

All datasets generated or analyzed during this study are included in the manuscript.

\section{ETHICS STATEMENT}

This article does not contain any studies with human participants or animals performed by any of the authors.

\section{REFERENCES}

1. Abbas Hisham A. Comparative. Antibacterial and Antibiofilm Activities of Manuka Honey and Egyptian Clover Honey. Asian Journal of Applied Sciences, 2014; 2(02), (ISSN: 2321-0893) 
2.

Al-kafaween Mohammad Abdulraheem, Abu Bakar Mohd Hilmi, Norzawani Jaffar, et al. N.d. Antibacterial and Antibiofilm Activities of Malaysian Trigona Honey against Pseudomonas aeruginosa ATCC 10145 and Streptococcus Pyogenes ATCC.

3. Alotibi Ibrahim A, Steve M Harakeh, Mohammed AlMamary, et al. Floral Markers and Biological Activity of Saudi Honey. Saudi Journal of Biological Sciences, 2018; 25(7): 1369-1374. https://doi.org/10.1016/j. sjbs.2018.05.021

4. Beretta Giangiacomo, Paola Granata, Maria Ferrero, Marica Orioli and Roberto Maffei Facino. Standardization of Antioxidant Properties of Honey by a Combination of Spectrophotometric/Fluorimetric Assays and Chemometrics. Analytica Chimica Acta, 2005; 533(2): 185-191. https://doi.org/10.1016/j. aca.2004.11.010

5. Bouacha Mabrouka, Hayette Ayed and Nedjoud Grara. Honey Bee as Alternative Medicine to Treat Eleven Multidrug-Resistant Bacteria Causing Urinary Tract Infection during Pregnancy. Scientia Pharmaceutica, 2018; 86(2): 14. https://doi.org/10.3390/ scipharm86020014

6. Cooper RA, E Halas and PC Molan. The Efficacy of Honey in Inhibiting Strains of Pseudomonas aeruginosa from Infected Burns. The Journal of Burn Care \& Rehabilitation, 2002; 23(6): 366-370. https://doi. org/10.1097/00004630-200211000-00002

7. Dilworth Thomas J, Steve N Leonard, A Mary Vilay and Renee-Claude Mercier. Vancomycin and Piperacillin-Tazobactam against Methicillin-Resistant Staphylococcus aureus and Vancomycin-Intermediate Staphylococcus aureus in an In vitro Pharmacokinetic/ Pharmacodynamic Model. Clinical Therapeutics, 2014; 36(10): 1334-1344. https://doi.org/10.1016/j. clinthera.2014.06.027

8. Geisel R, F-J Schmitz, L Thomas, et al. Emergence of Heterogeneous Intermediate Vancomycin Resistance in Staphylococcus aureus Isolates in the Dusseldorf Area. Journal of Antimicrobial Chemotherapy, 1999; 43(6): 846-848. https://doi.org/10.1093/jac/43.6.846

9. Horniackova Miroslava, Marcela Bucekova, Ivana Valachova and Juraj Majtan. Effect of Gamma Radiation on the Antibacterial and Antibiofilm Activity of Honeydew Honey. European Food Research and Technology, 2017; 243(1): 81-88. https://doi. org/10.1007/s00217-016-2725-x

10. Irish Julie, Shona Blair and Dee A Carter. The Antibacterial Activity of Honey Derived from Australian Flora. PLoS One, 2011; 6(3): e18229. https://doi. org/10.1371/journal.pone.0018229

11. Islam Asiful, Ibrahim Khalil, Nazmul Islam, et al. Physicochemical and Antioxidant Properties of Bangladeshi Honeys Stored for More than One Year. BMC Complementary and Alternative Medicine, 2012; 12(1): 177. https://doi.org/10.1186/1472-6882-12177
12. Jantakee Kanyaluck and Yingmanee Tragoolpua. Activities of Different Types of Thai Honey on Pathogenic Bacteria Causing Skin Diseases, Tyrosinase Enzyme and Generating Free Radicals. Biological Research, 2015; 48(1): 4. https://doi.org/10.1186/0717-6287-48-4

13. Khalil Md Ibrahim, Mohammed Moniruzzaman, Laid Boukraa, et al. Physicochemical and Antioxidant Properties of Algerian Honey. Molecules, 2012; 17(9): 11199-11215. https://doi.org/10.3390/ molecules170911199

14. Liu Je-Ruei, Yi-Ling Ye, Ting-Yu Lin, Yun-Wen Wang and Chi-Chung Peng. Effect of Floral Sources on the Antioxidant, Antimicrobial, and Anti-Inflammatory Activities of Honeys in Taiwan. Food Chemistry, 2013; 139(1-4): 938-943. https://doi.org/10.1016/j. foodchem.2013.02.015

15. Lo David KH, Marianne S Muhlebach and Alan R Smyth. Interventions for the Eradication of Meticillinresistant Staphylococcus aureus (MRSA) in People with Cystic Fibrosis. Cochrane Database of Systematic Reviews, 2018; 7. https://doi.org/10.1002/14651858. CD009650.pub4

16. Lowy Franklin D. Antimicrobial Resistance: The Example of Staphylococcus aureus. The Journal of Clinical Investigation, 2003; 111(9): 1265-1273. https://doi. org/10.1172/JCl18535

17. Mandal Manisha Deb and Shyamapada Mandal. Honey: Its Medicinal Property and Antibacterial Activity. Asian Pacific Journal of Tropical Biomedicine, 2011; 1(2): 154-160. https://doi.org/10.1016/S22211691(11)60016-6

18. Molan Peter C. The Antibacterial Activity of Honey: 2. Variation in the Potency of the Antibacterial Activity, 1992; 73: 59-76. https://doi.org/10.1080/000577 2X.1992.11099118

19. Molan Peter $C$ and Tanya Rhodes. Honey: A Biologic Wound Dressing, 2015.

20. Oryan Ahmad, Esmat Alemzadeh and Ali Moshiri. Biological Properties and Therapeutic Activities of Honey in Wound Healing: A Narrative Review and Meta-Analysis. Journal of Tissue Viability, 2016; 25(2): 98-118. https://doi.org/10.1016/j.jtv.2015.12.002

21. Price Jodi N and John W Morgan. Variability in Plant Fitness Influences Range Expansion of Leptospermum scoparium. Ecography, 2006; 29(4): 623-631. https:// doi.org/10.1111/j.0906-7590.2006.04645.x

22. Sakai Fumihiko, Hideshi Ihara, Kenji Aoyama, et al. Characteristics of Enterotoxin H-Producing Staphylococcus aureus Isolated from Clinical Cases and Properties of the Enterotoxin Productivity. Journal of Food Protection, 2008; 71(9): 1855-1860. https://doi. org/10.4315/0362-028X-71.9.1855

23. Wolff M, Gestion de I'echec Du. Traitement Des Infections $\alpha$ Staphylocoque. In Annales Francaises d'anesthesie et de Reanimation, Elsevier, 2002; 418423. https://doi.org/10.1016/S0750-7658(02)00629-9 